\title{
Intercultural Climate and Belonging in the Globalizing Multi-Ethnic Neighborhoods of Los Angeles
}

\author{
Felicity Hwee-Hwa Chan
}

Sol Price School of Public Policy. University of Southern California, USA

\begin{abstract}
Doubts about the efficacy of multiculturalism to address the tensions experienced between different social and cultural milieus or ethnoscapes in globalizing nations have grown. At the nexus of these tensions are multi-ethnic cities. Discussions of interculturalism at the urban scale have emerged as national governments search for ways to live in and with diversity in peace. However, less is understood about how interculturalism is actually lived out through the tensions in everyday encounters and negotiations in these globalizing multi-ethnic neighborhoods by people who live, work and/or regularly use these settings, which I posit in this paper as public-parochial realms. This paper presents empirical findings from a comparative qualitative study of three globalizing multi-ethnic neighborhoods in Los Angeles of different income levels by examining the following aspects (a) the circumstances of intercultural interaction in these neighborhoods from the perspectives of different ethnicities and (b) if and how local belongings are formed in these multi-ethnic spaces, in order to understand the possibilities for the formation of intercultural space in these diverse neighborhoods. The discussion foregrounds the globalizing multi-ethnic neighborhood as a meaningful frontier space for encounters that are capable of leading to either experiences of conflict or conviviality.
\end{abstract}

Keywords: Belonging, everyday encounters, globalizing multi-ethnic neighborhoods, interculturalism, Los Angeles, publicparochial realm.

\section{INTRODUCTION}

As one of the major gateways of immigration in the United States, Los Angeles stands at the crossroads of globalization. It is home to hundreds of nationalities and ethnicities and a global ethnoscape a la Appadurai of moving people cultures coming into contact with each other seeking to coexist in and through the limits of the urban space [1]. A city of multiplicities, the City of Angels appears to extol Israel Zangwill's virtues of a "melting pot" with its plethora of hybrid cultures and mixed marriages. Yet taken from another angle, Los Angeles undeniably was the site of two major civil unrests involving inter-ethnic violence in 1965 and 1992. Inter-ethnic relations remain an Achilles' heel for the city that also struggles with stark socioeconomic differences.

Appadurai in his discussion of the dimension of cultural globalization conceptualizes that the tension of cultural globalization lies in the struggle between cultural homogenization and cultural heterogenization [1-3]. Fleshing out this tension in a subsequent discussion by Holston and Appadurai, they pointed to cities as the "most intense points of implosion" resulting from the intersection of difference and density because of its voluminous inflow of immigrants that makes cities especially sensitive to the execution of immigration politics [4]. This is anecdotally witnessed in the increasing acts of overt and covert hostilities against the expressions of new ethnic or religious diversity such as

Address correspondence to this author at the Max Planck Institute for the Study of Religious and Ethnic Diversity, Germany;

Tel: +49 (551) 4956 - 134; E-mail: chan@mmg.mpg.de protests against mosques construction (e.g. New York, Los Angeles, Switzerland and Germany), struggles over neighborhood territories and belongings (e.g. Los Angeles, Italy, Singapore) and daily experiences of prejudiced behaviors against immigrants, especially those who bear the visible mark of a different culture and religion.

Living together in globalizing multi-ethnic environments is increasingly recognized as both a daily act of survival and an art of life. Dissatisfactions with the outcomes of multicultural policies and the ongoing abstract discourse of immigration integration and multicultural policies have impelled some scholars to search for tangible ways to understand and respond to exigencies arising from cities of difference [e.g. 5-7]. The title of Sandercock's paper When Strangers become Neighbors: Managing Cities of Difference succinctly articulates the challenging issue of negotiating the socio-spatial proximity of differences in the neighborhood [8].

Amin's discussion of the race disturbances in British suburbs in 2001 introduced the dimension of "everyday social contact and encounter" on the urban local scale as purposive means to reduce prejudice to the otherwise vague discourse on immigration integration [9]. As an alternative to multiculturalism, Amin [9] proposed "urban interculturalism" that he described as follows,

"The term 'intercultured' I used to stress cultural dialogue, to contrast with versions of multiculturalism that either stress cultural difference without resolving the problem of communication between cultures, or versions of cosmopolitanism that speculate on the 
gradual erosion of cultural difference through interethnic mixture and hybridization...My emphasis, in contrast, falls on everyday lived experiences and local negotiations of difference, on microcultures of place through which abstract rights and obligations, together with local structures and resources, meaningfully interact with distinctive individual and interpersonal experiences...It is intended to privilege everyday enactment as the central site of identity and attitude formation." (p.967)

Interculturalism as an everyday practice of negotiation has found increasing resonance in empirical studies at the neighborhood level by sociologists, social geographers and planners in Europe, Australia and Canada [7, 10-15]. This paper builds on these writings by examining the state and scope for interculturalism in globalizing multi-ethnic neighborhoods in metropolitan Los Angeles which is known for its urban tendencies to socially, economically and spatially separate people and cultures. It foregrounds these globalizing multi-ethnic neighborhoods as meaningful routine "common ground" where different ethnicities have either chosen or found themselves with little choice but to learn to negotiate coexistence and belonging. The increasing ubiquity of these multi-ethnic urban settings urges better understanding of these spaces as they present an immediate challenge to urban planning and policy that have hitherto been more familiar with planning in homogeneity than in diversity.

\section{PARAMETERS AND METHODOLOGY}

The following discussion presents an ongoing analysis about the socio-spatial dynamics of living in diversity and the opportunities that the multi-ethnic neighborhood. It posits that globalizing multi-ethnic neighborhood share concurrent characteristics of both a parochial realm and a public realm that Lofland [16] writes about. A public realm according to Lofland is where the predominant form of relations "found in some physical space are with strangers or categorical" (p.14) and a parochial realm is a communal space that is "characterized by a sense of commonality among acquaintances and neighbors who are involved in interpersonal networks that are located within “communities"” (p.10).

In this paper, I refer to globalizing multi-ethnic neighborhoods as "public-parochial realms" that exist in a continuum between the public and parochial realm that Lofland conceptualizes about [16]. These neighborhoods by being at once a public realm of strangers and a parochial realm of local belonging to a communal social space produce tensions of inclusion and exclusion that has implications for the formation of an intercultural space.

This paper draws from the qualitative fieldwork completed over two phases in three neighborhoods of different median household income levels in Los Angeles Central Long Beach is low income, Mid-Wilshire is mixed income and San Marino is high income. ${ }^{1}$ Please see Fig. (1)

${ }^{1}$ US Census 2010 reports that the median household income in Central Long Beach is $\$ 33,000$ (approx. about 60 percent of Los Angeles County), in for the geographical locations of these three neighborhoods in Los Angeles County.

In May 2011, preliminary interviewing was conducted in each of the three multi-ethnic neighborhoods with 15 adults. Between August 2011 and mid-February 2012, I interviewed residents, users, business owners, community organizers, municipal officers, participated in neighborhood events (e.g. fundraisers, festival, parade, farmers' markets), attended neighborhood meetings and conducted surveys. In total, 98 semi-structured interviews about the perception, experience and opportunities of intercultural living in these three diverse neighborhoods were completed. Each neighborhood had approximately equal number of interviews and representation of the relevant major ethnic categories (Whites, Hispanics/Latinos, African Americans/Blacks and Asians). Of the 98 semi-structured hour-long interviews, 34 were in Central Long Beach, 34 in Mid-Wilshire and 30 in San Marino. ${ }^{2}$ Access to interviewees in each neighborhood was designed to source from different venues including public spaces (libraries, parks, community centers) and civic organizations (religious and social services organizations) to minimize narrow selection and biased viewpoints.

\section{ASSESSING THE INTERCULTURAL CLIMATE OF MULTI-ETHNIC NEIGHBORHOODS}

\section{Central Long Beach: Low-income and Dense}

The Central Long Beach neighborhood along East Anaheim Street is a low-income area made up of Latinos (mix of Americans and immigrants from Mexico and Central America such as El Salvador, Guatemala and Honduras), Asians (majority Cambodian immigrants, Thais and Vietnamese) and African Americans living in dense rental apartments. Social space is a profound concept here because of the pervasive territorial gang activities and street violence along ethnic lines in the neighborhood that has accompanied the phases of Latino and Asian immigration into the neighborhood between 1970s and 2000.

Before the 1950s and 60s, the neighborhood had mainly White population but subsequently became mixed with African Americans. Latinos came after and coincided with a sudden influx of Cambodian refugees from late 1970s through 1990s. Interviewees recalled the neighborhood in 1980 s and 1990s as a "war zone." Literally, funerals of victims killed in crossfire between Latino and Cambodian gangs fighting over territories would occur every week. The public-parochial realm of the neighborhood was abused by the frequent bullying, racial slurs, beating and shooting that would occur in the streets that involved both gang and nongang members. While relations between Latinos and Asians have improved over the last decade due to municipal interventions in the schools, through community outreach and police patrolling, the relations between African Americans and Latinos remain uneasy, creating a somewhat passively tense social climate in the neighborhood. A young

Mid-Wilshire it is between $\$ 26,000$ to $\$ 130,000$ (approx. 50 percent to 230 percent of LA County) and in San Marino, it is about \$150,000 (approx. 270 percent of LA County) [17].

${ }^{2}$ Some of the interviewees did not complete the entire interview because of time constraints. As such, the data to examine local belonging has 49 responses rather than 98 . 


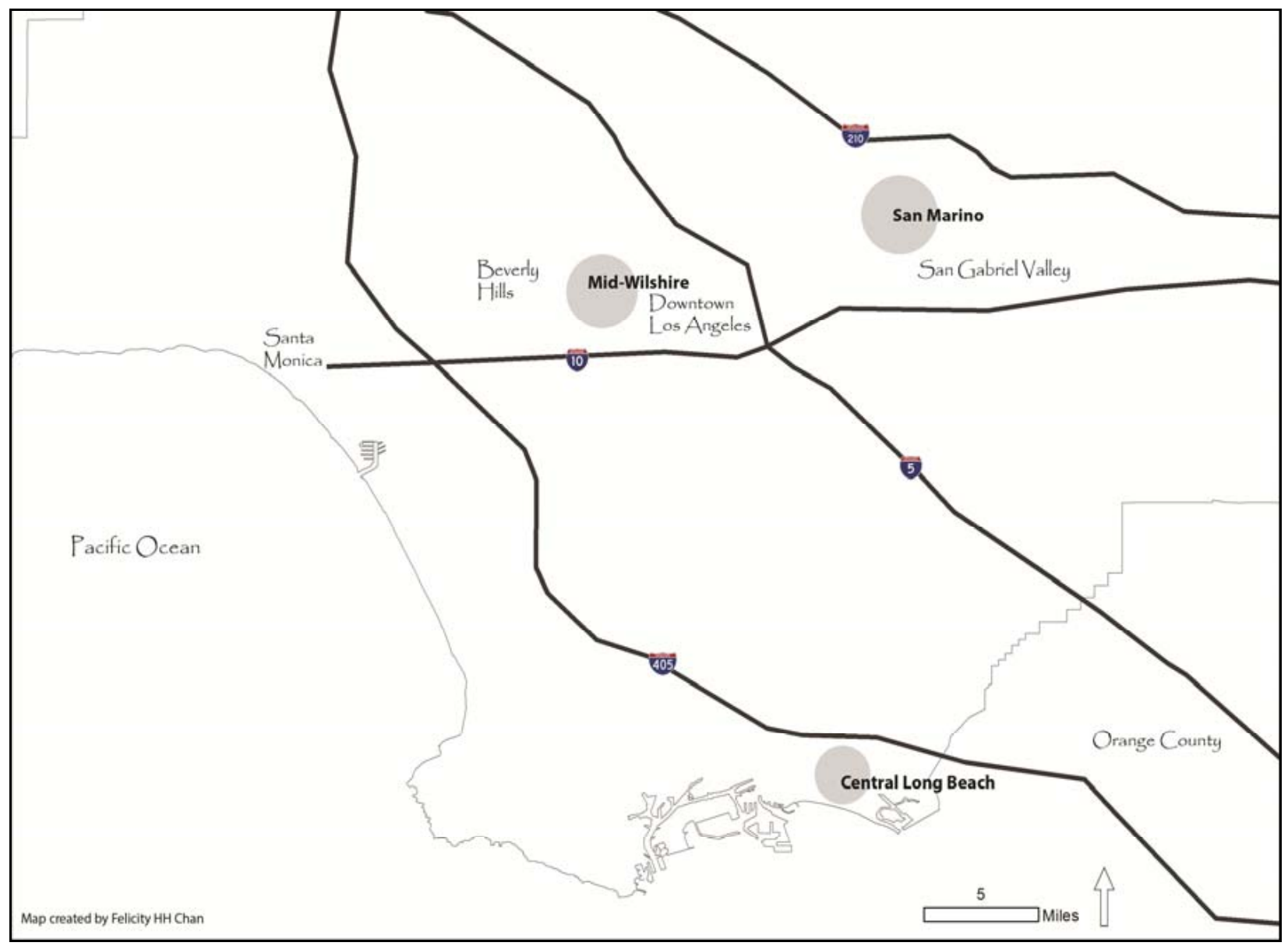

Fig. (1). Map showing the locations of the three neighborhoods in Los Angeles County.

African-American woman who grew up in the neighborhood hinted at the tension between Blacks and Mexicans,

“To be honest, I really don't keep my eyes on the Cambodian people and Asian people coz' they are really not in conflict of the international racial part we have going on in our building, in our surrounding areas. It is majority Mexicans and Blacks. The Cambodian people and Asians, you know, they keep to themselves."

While the streets has become less violent, conception of different cultural and ethnic belongings continue to be contested issue that plays out in the multi-ethnic neighborhood space as illustrated in the protracted negotiation to designate a one-mile long strip of East Anaheim Street neighborhood as "Cambodia Town." The proposal to create a Cambodian cultural place by a group of Cambodian businessmen in a multi-ethnic space of Latino, Asian and African-American interests triggered a new round of unease and fears that this "parochial" conception by a group of businessmen who do not live in the neighborhood may lead to a dismantling of the fragile public social space that belongs to everyone regardless of ethnicity. However, the proposal was finally adopted and implemented by the city in 2011 after a decade of negotiation between multiple stakeholders [18].
The fragility of the inter-ethnic relations coupled with language barriers between the different ethnicities, many of whom are not fully conversant in English, Spanish or Khmer have created a lived space that can oscillate between at best lukewarm and at times heated intercultural climate. As a result, intercultural contact if it happens is usually brief "hibye contact" and is largely limited to those living next door or in the same apartment building. An African-American man replied when asked whether it is difficult to get to know neighbors in the area,

"It can be. Sometimes they are really stiff about exactly who they are going to socialize with. I notice there are a lot times when I try to socialize with people, their attitude is 'You are policeman? Are you a policeman?' is kind of like, whoa, I am just some guy who lives in the neighborhood....As far as meeting people around here, it is kind of normal in a way that, you know, certain people like to stick to just their own people and the ghettos are kind of like that coz this part of town is rather ghetto, so the ghetto that is just the way it goes, people just stick to their own racial and people they are familiar with...they are not so much into meeting new people." 
This view that there is a lack of intercultural engagement in the neighborhood is also shared by Mexican and Cambodian interviewees. Socializing and friendships are usually within the ethnic group. The interviews also suggest that different ethnicities have different routine geographies such as ethnic markets and restaurants even though they live in close proximity. Except for the neighborhood library and park, there is a general lack of public spaces where different age groups and ethnicities can be seen using them although activities in these public spaces are observed to be usually organized along ethnic lines. There is an overall sense of intercultural apathy amongst those who live there as an interviewee surmises,

\begin{abstract}
"Not really, everyone speaks to each other... you know I have been living here for over many years now, so everyone knows each other, you know, when all is said and done, they stay put with their kind and they stick with their kind."
\end{abstract}

\section{Mid-Wilshire: Mixed Income and Multiple Environments}

Mid-Wilshire, an area between Downtown Los Angeles and Beverly Hills is a culturally and economically diverse area that juxtaposes the very poor and the very affluent in Los Angeles. The income spread is reflected in the spread of housing types and living conditions in the area. Dense multifamily apartments in the east transition sharply to a sliver of condominiums that then quickly gives way to large and larger mansions in the west. Matching this income spread quite well is the broad geographical pattern of ethnic composition from east to west. From the east, Latinos (from Mexico and Central America) transition to Asians (Koreans and Filipinos), followed by a mix of White Anglos and Jews towards the west, with a sprinkling of African-Americans throughout the study area.

The social space in Mid-Wilshire is highly territorialized and differentiated by multiple cues in the landscape such as building types, people density, ethnicities, business signages displaying different languages. The "public-parochial" realm of this neighborhood is conceived as a mosaic of parochial neighborhood associations, business districts and ethnic enclaves (e.g. Korea town, Little Bangladesh) by the city and community organizers. These mosaic spaces are even more intricately experienced by the resident interviewees who would identify vertical territories of apartment buildings on their neighborhood block with concentrations of Koreans or Latinos.

Most interviewees expressed that their everyday lived experiences of inter-ethnic relations in the area are made up of rare and quick "hi-bye contact" limited to a couple of neighbors in their apartment building. From their experience, there is generally little to no racism directed at them or others explicitly. However, daily tension and prejudices are clearly alive as several interviewees of different ethnicities would recount how Latinos have the tendency to drink and party late into the night or how Koreans in their apartment building are cold and unfriendly. There is also an anxiety amongst the residents and businesses when AfricanAmericans are seen in the neighborhood according to several of the interviewees and the police officer I interviewed. An interviewee who has worked in the neighborhood for 16 years said the following when I asked her if race or ethnicity an issue in this neighborhood,

"It can be. I think that there is very few African American people here...In Larchmont recently in one of the homes, there was a home burglary. Actually I don't think they got in but the cameras captured the individuals. The two individuals were African American men in their twenties and then there was some crime on the Boulevard recently and there were photos of an African American man.... and so I say amongst owners of businesses on the Boulevard, if they see an African American man in their twenties, they are likely to look him over very carefully and be very suspicious because of recent crimes and because of just our general society's stereotypes about African American men in their twenties... The diversification of this area is AfricanAmerican challenged.”

Similar to Central Long Beach, intercultural engagement is passive, infrequent and non-existent apart from a few interviewees who have chosen to live in this area because of its diversity. Further, different ethnicities have different lived geographies. For example, almost all the White Anglos interviewees routinely frequent Larchmont Boulevard, a quaint main street in the area with boutique shops and restaurants, while fewer Asian interviewees do so and even fewer Latinos go there. A Korean interviewee described going to Larchmont is like going to Europe! The same can be said for Koreatown, where all the Korean interviewees would use the services and spaces daily but few Filipinos or Latinos or White Anglos would frequent despite its proximity to their residence.

Where intercultural engagement does happen, it is often in the playground or parks. Interviewees recount times when they would start a conversation with fellow mums or nannies if the kids are playing together or when they have been invited to join in a game of basketball in a park.

\section{San Marino: Affluent and Exclusive Enclave}

The City of San Marino is a small affluent enclave of over three thousand households living in large and oftentimes luxurious homes that prides itself in its high education standards, property values and the distinction it makes between residents and non-residents. Since the 1980s, San Marino a previously homogeneously White Anglo neighborhood has slowly become majority Asian (mainly Chinese) when affluent immigrants from Taiwan, Hong Kong and more recently China buy homes in the area. San Marino is known colloquially by many of its residents as "Chan Marino" because of the growing Chinese population in the city.

This demographic shift over the years has created an undercurrent of angst amongst the White Anglo population, especially the elderly who see the neighborhood becoming more diverse in age and ethnicity (because of the younger Asians) and finding a shrinking common social space. Anecdotal evidence has revealed that differing attitudes over important community concerns about property maintenance, different aesthetic preferences e.g. for trees or concrete, and 
culture of education have fueled the undercurrent of passive hostility between the two major ethnic groups. A young White Anglo man who was raised in San Marino said the following when asked if he knew of any expressions of hostility or friction between the White Anglos and the Chinese,

"It is hard to say, I mean... Not that I have heard... I mean I have heard people saying, the older San Marinos usually isn't quite as happy about that. I am not sure...I think is because...I don't know...I mean the older San Marino residents grew up when it was primarily white. They do see the change. I have heard that people have made racist comments about it but not that I have heard from anybody. But friends would say things like that and I don't know how true that is or widespread it was but I wouldn't doubt it. But I really don't know about that. If it is widespread I would have heard about it...I mean if people are saying anything, they are saying under their breath."

Covert hostility and at times overt experiences of discrimination were felt by many of the Chinese interviewees when they first moved into the neighborhood. In fact, the origins of the Chinese Club of San Marino could be traced back to the purpose of helping co-ethnics survive and promote understanding between the two groups. A Chinese American resident who has lived there for fifteen years said the following,

\begin{abstract}
"When I came here I was disgusted....Some of the Chinese by the time I came here in the late 80 s and early 90s, they have been here for twenty years. But they were not treated equally... so the Chinese move in and Taiwanese move in to the San Marino area and then what happens is that because of that there is a white exodus like around middle school. A lot of white would go to private schools for two reasons. Number one: Because there are too many Asians. Socially they don't want their kids to mix with Asians and then number two is because the schools with so many Asians, it is too competitive."
\end{abstract}

Through the interviews, many Asian interviewees articulated a sense of discomfort when they are with White Anglos. They alluded to the difficulty to reconcile differences in language, worldviews and social preferences between the eastern and western culture. Some White Anglo interviewees expressed how they find it difficult to connect with Asians because they have tendencies to keep to themselves and the different values Asians have. However, polite face-to-face relations and moments of intercultural conviviality are present during several organized community events such as July $4^{\text {th }}$ celebration and fundraisers. Thus beneath the veneer of polite acknowledgement, lies two disparate lived spaces akin to Cantle's "parallel lives" [19]. Informal spontaneous intercultural engagement between neighbors is rare perhaps as a result of the lack of a public realm that lies outside special interests groups such as schools, parents-teachers associations (PTAs), Little Leagues (baseball competitions for children), Rotary Club and the Chinese Club of San Marino. Essentially, most social interaction and public life in San Marino unfold in parochial and private clubs.

Nevertheless, there are more possibilities of intercultural engagement for families with children because of the multiple volunteer opportunities and activities that Parents' and Teachers' Association (PTA) offer year-round to work together on common projects that benefit the children's education. All the interviewees who have or had children attended the San Marino schools would relate their interethnic and intercultural experiences in San Marino to the school activities. While these activities offer opportunities for more substantive interaction and incentives for reconnection across cultural boundaries, these connections rarely developed into something deeper that last beyond the schooling years of the children. However, these activities remain the few common bridges that enable the two parallel worlds to be connected in a purposeful process of intercultural living and integration.

\section{FORMING BELONGINGS IN MULTI-ETHNIC NEIGHBORHOOD SPACE}

Sharing living space in multi-ethnic and multi-national settings can invoke feelings of overt and passive anxiety of the stranger foreigner who displays culturally different habits and behaviors $[5,20]$. Arising from the ambiguity associated with the public-parochial realm, the "lived" space of multiethnic neighborhoods is a continual process of defining who belongs and who does not. Thus, how belongings are formed at the local neighborhood level has implications for the formation of intercultural spaces in these diverse neighborhoods.

Belonging is frequently conceptualized as a basic human need that is constructed in social space. According to Maslow [21], "the needs for safety, belongingness, love relations and for respect can be satisfied only by other people i.e., only from outside the person (p.34). This means considerable dependence on the environment." Yuval-Davis [22] describes belonging as "an act of self-identification or identification by others, in a stable, contested or transient way" (p.199). In a study of the effects of globalization on local belonging to a residential place, Savage et al.'s [23] approach local belonging "as fluid and contingent" and "a socially constructed, embedded process" (p.12). They are of the view that "residential place continues to matter since people feel some sense of 'being at home' in an increasingly turbulent world." These findings are the subject of further study on the politicized nature of belonging and homemaking by Duyvendak [24].

In the writings of how local belonging is formed, there are several familiar strands. First, belonging is a choice [23, 26]. Savage et al. conceptualize this choice as "elective belonging" where the middle class people they interviewed articulate the right to move and settle in a place that they accord functional and symbolic meanings [23]. Choice is the power to decide and to choose according to Fenster [26] and "the more choice people have the stronger their sense of belonging becomes" (p.227). Second, belonging is a routine practice and freedom of using and inhabiting urban spaces [26]. Third, Devadson [25] suggests that for minorities and 
migrants, their belongings are formed through "their own engagement with the places where they live" and "reflect a perception of being accepted by the majority" (p. 2954). Fourth, belonging can also be formed through the sharing of ethnicity and common cultures as exercised through the definition and maintenance of social boundaries over time [27]. These ethnic identities and belongings according to Gupta and Ferguson will become more territorialized with growing global immigration [28].

These writings indicate that belonging formation is substantively articulated in the social and physical dimensions of the public-parochial realm. The analysis of how local belongings are formed in the three multi-ethnic neighborhoods in Los Angeles reveals that interviewees' feelings of local belonging are oftentimes tied to the relations they have with the public-parochial realm. Table $\mathbf{1}$ shows a summary of the distribution of replies and a tabulation of the list of reasons to the following questions, "Have you ever felt like an outsider in this neighborhood?" and "Do you feel like you belong? Why and what makes you feel like you belong?"

From the list of reasons, three reasons emerge common in all three neighborhoods as critical for the formation of local belonging. They are namely having good interpersonal relations with neighbors, presence of ethnic commonalities and differences as well as having local knowledge of the neighborhood such as knowing the people, where to go and more. Together, these reasons suggest that formation of local belonging is in fact more socially and communally orientated than what has been suggested in some of the writings and that the formation of local belonging can be shaped by the intercultural climate of the public-parochial realm of the neighborhood.

\section{Interpersonal Relations with Neighbors}

Relationship with one's neighbors is a double-edged sword in the way it can either help to form local belonging or not. This is especially the case when the individual is a minority. For example, the White Anglo interviewees at Central Long Beach, who are the minority ethnicity in the neighborhood, expressed their local belonging in the context of social acceptance by other ethnicities and the good relations they had developed with the neighbors who were non-White [25]. According to a White Anglo resident who has moved into the neighborhood in the last two years,

"I am accepted by the Cambodian community - all facets of it. I am like a son almost to a lot of them.... The Hispanics know that I am a cool guy and Black people know I am a cool guy. All kinds of people who know me cover for me. It is pretty ok for me to go anywhere."

Conversely, the lack of local belonging is acutely felt when relations with neighbors are non-existent or tense and

Table 1. Feelings and Reasons of Belonging in the Three Neighborhoods

\begin{tabular}{|c|c|c|c|c|c|}
\hline $\begin{array}{l}\text { Do you Feel Like you } \\
\text { Belong? (Response) }\end{array}$ & $\begin{array}{l}\text { Central Long } \\
\text { Beach (CLB) }\end{array}$ & $\begin{array}{l}\text { Mid-Wilshire } \\
\text { (MW) }\end{array}$ & $\begin{array}{l}\text { San Marino } \\
\text { (SM) }\end{array}$ & $\begin{array}{l}\text { Total No. of } \\
\text { Responses }\end{array}$ & $\begin{array}{c}\text { Reasons Cited in Order of Frequency (Neighborhood/s } \\
\text { where Reason is Cited) }\end{array}$ \\
\hline Yes & 10 & 9 & 9 & 28 & $\begin{array}{l}\text { :Having interpersonal relations with neighbors (CLB, } \\
\text { MW, SM) } \\
\text { :Ethnic commonalities and differences (CLB, MW, SM) } \\
: \text { Having local knowledge of the neighborhood (CLB, MW, } \\
\text { SM) } \\
: \text { Participating in the neighborhood community (CLB, SM) } \\
: \text { Feeling a sense of home (CLB, SM) } \\
: \text { Having the right to belong (CLB, MW) } \\
: \text { Having access to public spaces and amenities (CLB, } \\
\text { MW) } \\
\text { :Sharing same values as neighbors (MW, SM) } \\
\text { :Living or working in neighborhood (MW, SM) } \\
\text { :Proximity to friends and families (MW, SM) } \\
: \text { Owning property (SM) } \\
: \text { Birthplace (CLB) } \\
: \text { Choosing to belong (CLB) }\end{array}$ \\
\hline Yes and No & 2 & 6 & 6 & 14 & $\begin{array}{l}\text { :Ethnic commonalities and differences (CLB, MW, SM) } \\
\text { :Wealth differences are too stark (CLB, MW) } \\
\text { :Language difficulties in communicating with neighbors } \\
\text { (MW) } \\
\text { :Different demographic characteristics (SM) } \\
\text { :No community engagement (SM) }\end{array}$ \\
\hline No & 2 & 3 & 2 & 7 & $\begin{array}{l}\text { :Bad or lack of interpersonal relations with neighbors } \\
(\mathrm{CLB}, \mathrm{MW}, \mathrm{SM}) \\
\text { :Different values of living (CLB, MW) } \\
\text { :Too many pockets of ethnic concentrations (MW) }\end{array}$ \\
\hline TOTAL & 14 & 18 & 17 & 49 & - \\
\hline
\end{tabular}


can lead an individual eventually to decide not to belong. An African American man in his 30s who was born and raised in Central Long Beach expresses this sentiment,

Interviewer: Have you ever felt like an outsider in this neighborhood?

Respondent: All the time. You are taught to stay away from certain people because you don't want a conflict. Instead you tend to stay around your own, in your own little area, in your own cubicle.

I: Who are these people? Is it ethnicity or race?

$\boldsymbol{R}:$ No. It is the ignorant mentality of certain people. It is not really a race. They always have to cause problem in order to feel good.

I: Do you feel like you belong?

R: I don't think so. I think I should be somewhere else.

However, a warm welcome also goes an extra mile in helping the formation of local belonging in newer residents. Perhaps significant in its impact because of its rarity, the atmosphere and act of initial welcome by neighbors to the neighborhood has left a deep impression on several of the interviewees. They affirm their local belonging quickly when asked and with great certainty and fondness recall the respect, appreciation and warmth that they received upon arrival in the neighborhood. Even though these encounters are brief, they are powerful in that they are able to counteract other bad experiences to configure a rare but positive intercultural space.

In fact, receiving these acts of welcome has changed the way a Chinese American interviewee in San Marino viewed neighborly relations. Raised in New York City and having lived in different cities around the word, she did not think that neighbors are people who care or one would have a need of them until she relocated to San Marino where she was welcomed by her new neighbors. That experience was so powerful that she expressed with conviction that she felt like she belonged more in San Marino than any other previous places she had ever lived in. Her sentiments were shared by a recent immigrant from China in San Marino who was grateful for the effort her neighbor took to engage her about Chinese culture. This was an important act of kindness and intercultural engagement that remained with her despite the experience she and her family have encountered as a new immigrant with little spoken English when she first arrived in the neighborhood.

\section{Ethnic Commonalities and Differences}

Ethnicity like neighborly relations is a nuanced element in the formation of local belonging, especially in multiethnic neighborhoods. It joins and it divides. In MidWilshire where the myriad of languages and ethnicities has created geographies of "ethnic and racial moorings" (p.1016) amidst diversity [29], Korean and Hispanic interviewees have expressed a local belonging that is tied to the proximity and presence of co-ethnics and the comfort of using Korean and Spanish to navigate the city [27]. A Korean immigrant who has been living in the Mid-Wilshire neighborhood for about four years described the subtle complexity that the presence of cultural similarities and differences can create for the formation of local belonging particularly for an immigrant,

"Half and half. I live in here. Because my
husband's friends are born here but I
sometimes misunderstand them [because of
English]. I belong because many people speak
Korean in LA."

Her views are shared by the Chinese immigrants too in San Marino where the presence of cultural and language differences make it difficult to feel entirely comfortable to socialize and have substantive conversations between neighbors. These instances of discomfort and at times embarrassment, a result of not understanding the exchange in English, can raise questions of one's sense of belonging in an intercultural group and simultaneously can enhance one's belonging to an ethnic group.

Ethnicity (un)fortunately frequently does not act alone but can interact with socio-economic factors and manifest in the use of space as suggested by Fenster [26] and Barth [27]. This is illustrated in Central Long Beach and Mid-Wilshire where geographies of wealth disparity follows ethnic lines and can narrow one's sense of local belonging to a more parochial realm within the larger neighborhood. A secondgeneration Mexican American contrasts her feeling of local belonging between the Mid-Wilshire area she lives in that is made up by mostly lower-income Hispanics and the nearby Larchmont area made up by mostly affluent White Anglos, Jews and Asians that she visits sometimes,

"When you are here [pointing to the area on she lives in on a map], you feel like you are majority coz' of the people around you, your population. Plus like they know what you go through sometimes. When you come here [pointing to the Larchmont area], you feel like a minority coz' you see everybody with the nice houses and nice cars. You don't see like they say your own people around this neighborhood."

Thus, the presence of ethnic diversity presents a nuanced challenge to the formation of local belonging in a multiethnic neighborhood. The absence of co-ethnic in the presence of other ethnicities can result in the questioning of one's belonging in the local realm and the presence of coethnics in the neighborhood can make one feel a sense of local belonging. It leads one to question if this is the only kind of parochial local belonging that we can expect from a multi-ethnic neighborhood and if so, what does that imply for the creation of an intercultural space.

\section{Having Local Knowledge of the Neighborhood}

Having a good knowledge of the neighborhood in terms of how it works, the people who live around you, where things are located and simply what is the pulse of the neighborhood can help to form feelings of local belonging especially for the immigrants in these multi-ethnic neighborhoods [25]. Local knowledge and familiarity come with time spent in the neighborhood and building relationships and networks require time. The findings show 
that among those who feel they belong because of their local knowledge of the neighborhood have lived and/or worked in the neighborhood for at least a decade.

An interviewee from Central Long Beach (an Asian immigrant) who has been working there for about 20 years but lives in another part of Los Angeles felt that the length of time in the neighborhood has enabled her to get to know and earn the trust of her customers and her customers' families and their lives. The neighborhood is now part of her life where she spends more time there than at home. These reasons give her a strong sense of belonging to the neighborhood. Getting to know the neighborhood, the nooks and crannies, the people and community not only grows an attachment but also empowers an individual with confidence from having that knowledge to navigate the diverse publicparochial realm. This was the view shared by several interviewees in Central Long Beach and Mid-Wilshire.

Local knowledge also comes from participation in the social activities in the neighborhood such as fundraising, neighborhood clean-up and school activities. This is especially significant in San Marino where volunteerism is exalted and valorized in an affluent neighborhood that regards more highly time and sacrifice made for children's education than financial wealth per se. In San Marino, to belong is to participate and as such, through participation in the community, an individual gains social exposure, increase one's contact with neighbors and earn social acceptance. In fact, one interviewee who was unsure about her local belonging to San Marino expressed that it could be due to her not taking part in any community club or group even though in every way, San Marino is a safe space and it is her home.

While these findings reaffirm Maslow's view that belongingness is very dependent on the environment and other people for the most part [21], they also highlight Fenster's and Savage et al.'s findings that belonging is also a decision of choice $[23,26]$. Oftentimes as the interviewees in this study have explained, belonging is a matter of fit between the values of the neighborhood and the individual. In Mid-Wilshire and Central Long Beach, the interviewees who expressed their choice to not want to belong would explain that the values of the neighborhood are at odds with how they would like to live. The indifference and tension between neighbors, the noise and dirt were the examples that interviewees gave for not wanting to belong. In contrast, interviewees from the wealthier half of Mid-Wilshire expressed their strong sense of "elective belonging" because they share the values of the neighborhood of professionalism, respect for differences and responsible treatment of public amenities. Similarly in San Marino, local belonging is often elective and a choice practiced by the interviewees who buy into San Marino for the values (both pecuniary in terms of property values and philosophical in terms of its focus on education and family-oriented) it offers.

However, individual choice to belong may or may not result in obtaining the feeling that one belongs because local belonging is dependent on the wider environment and other people. This is illustrated in the findings that five out of the six interviewees who share a sense of ambivalence in their local belonging in San Marino are first generation immigrants from Taiwan and China who for reasons mentioned above about differences in culture, language and age find it difficult to fully feel like they belong. This is a stark contrast with the White Anglo residents in San Marino who expressed their strong sense of belonging and inclusion in San Marino.

\section{CONCLUDING COMMENTS: POSSIBILITIES FOR AN INTERCULTURAL SPACE?}

The three multi-ethnic neighborhoods of different socioeconomic levels in Los Angeles offer glimpses into the tensions of globalizing spaces of cultural heterogeneity as people struggle daily to live with multiple differences of ethnicity, cultural expectation, worldview, and language to in a shared space [9]. This is seen in the different as well as overlapping types and degrees of tension exhibited in the sharing of the public-parochial realm in Central Long Beach, Mid-Wilshire and San Marino.

While overt racism is not experienced in any of the neighborhoods, each neighborhood struggles with an undercurrent of a subtler form of hostility between the ethnicities. In Central Long Beach, the decades of gang violence and language barriers have left a wariness and weariness in its residents to engage with each other across ethnicities. In Mid-Wilshire, the dense living conditions in the eastern part have accentuated the differences in cultural lifestyles that may have led to a perpetuation of common negative stereotypes about one ethnic group or another. In San Marino, the little need to share common resources and living space has encouraged a condition of "parallel worlds" to emerge along ethnic lines [19]. Overall, the intercultural climate in Los Angeles appears to be largely passive, ephemeral and highly dependent on an individual's desire and ability to initiate.

This is not to say that there are no moments of conviviality between ethnicities in Los Angeles but to highlight that much more work on interculturalism remains to be done. Broadly, Los Angeles's multi-ethnic neighborhoods seem to fit Amin's description of "versions of multiculturalism that either stress cultural difference without resolving the problem of communication between cultures, or versions of cosmopolitanism that speculate on the gradual erosion of cultural difference through interethnic mixture and hybridization" (p.967) [9]. Overall, these neighborhoods display an intercultural apathy.

The discussion on the formation of local belonging has enabled a deeper foray into what some of the reasons for intercultural apathy might be in these globalizing multiethnic spaces by asking questions about how relations with the local environment are formed. It illustrates that multiethnic space as a hybrid "public-parochial realm" of strangers and known others in a communal space is a complex social space where interpersonal relations with neighbors, ethnicity and knowledge of the neighborhood matter a lot in the formation of local belonging [16]. The discussion affirms the findings of other writings on the formation of belongings but suggests that the affirmation of feelings of local belonging is perhaps more dependent on others in multi-ethnic settings than on oneself based on the findings in the three multi-ethnic neighborhoods included in this study. 
The findings about the formation of local belonging seem to suggest that multi-ethnic spaces are inherently communal and embedded daily with a continual process of boundaryguarding and boundary crossing in both tangible physiologically ways as well as intangible abstract ways. It hints at a desire in people to connect and the importance relational connection has for flourishing neighborhoods. However, my sense is that these ongoing processes are not fruitfully disrupted by opportunities or catalyzed into real dialogues for them to be transformative. Instead, living through difficult processes of daily boundary-guarding and boundary-crossing can only eventually lead to numbing inward-directed tendencies in individuals as these experiences take their toll.

Is an intercultural space possible to seed within the interstices of these multi-ethnic spaces that are at once parochial and public, making the process of inclusion and exclusion more complex? This is my present take on the three neighborhoods based on the findings thus far:

In Central Long Beach where public space is limited to municipal facilities, public life have little to no social space to flourish other than in the semi-public space of ethnic grocery shops and restaurants. The experience of inclusion and exclusion is at once physical and social. Its intensity reinforced by wariness against a recent past of ethnic street violence that threatens to erupt again ever so often. In fact, exclusion is not an uncommon experience because of how all semi-public space of services is ethnically anchored e.g. Cambodian restaurant, Mexican grocery shop, Asian-run liquor stores, and Southern soul food. Thus, the feeling of exclusion is part and parcel of partaking in public life. This may be perhaps why good relations with neighbors are deemed significant in shaping local belonging and being part of a larger whole. The hope for intercultural space may require efforts to enlarge and reshape the existing public space e.g. parks, library and community center in ways that intentionally planned for intercultural engagement [18].

In Mid-Wilshire, public life takes place in ethnic clusters that are spatially more concentrated than in Central Long Beach. It is a dense area of multiple overlapping territories where you can easily find yourself in someone else's "hood." To partake in public life is to experience inclusion and exclusion within a block or within a single minute. Korean restaurants line certain streets with large signs in Korean only, Hispanic shops (to be exact El Salvadoran, Mexican, Guatemalan) are located in different clusters, expensive eateries and boutiques are clustered Larchmont Boulevard, and along certain streets, one finds Korean shops juxtapose with Latin and Central American eateries. The potential of intercultural space in Mid-Wilshire lies in encouraging purposeful boundary-crossing that needs to go beyond the reliance and desire of the individual. The area is highly fragmented socio-economically and ethnically. Concerted institutional efforts to plan opportunities and create places where people are attracted to "pause" in their daily rhythms [16] and engage with others are necessary for an intercultural space to emerge. In strategic locations where lines of fragmentation are particularly stark, for example along certain streets, a world market and/or street potluck, for example can be organized by closing off a street periodically but regularly to raise the importance and conviviality of living with different cultures.

In San Marino, public space in the neighborhood is akin to a giant network of social connections. The tendency for exclusion in the public sphere in San Marino can be significant if one does not partake in community activities, clubs and/or special interest organizations. Some of the interviewees view San Marino as a conservative place, where there is a preference to exclude what is different and conform to the existing values of the community. The sense of "elective belonging" to San Marino shared by many of its residents discussed earlier acts to further preserve the status quo [23]. Thus, the potential for interculturalism is as great as the odds stacked against it. San Marino is a city that values its privacy. While it has the resources to enable more opportunities for intercultural engagement, there needs to be a willingness on the part of individuals and institutions to recognize that there is still work on intercultural relationshipbuilding to be done beyond the opportunities schools provide. This is because school opportunities are frequently not inclusive of the many others such as the elderly or those with no children to partake.

\section{CONFLICT OF INTEREST}

The author confirms that this article content has no conflict of interest.

\section{ACKNOWLEDGEMENTS}

I would like to thank Professor Tridib Banerjee for his invaluable insights on the writing of this paper and the University of Southern California for its financial support through the Dissertation Completion Fellowship 2012-13.

\section{REFERENCES}

[1] Appadurai A. Disjuncture and Difference in the Global Cultural Economy. Public Culture 1990; 2: 1-24.

[2] Appadurai A. Modernity at Large: Cultural Dimensions of Globalization, Minneapolis, University of Minnesota Press 1996.

[3] Appadurai A. Global Ethnoscapes: Notes and Queries for a Transnational Anthropology. In Fox, R. Ed. Recapturing Anthropology: Working in the Present, Santa Fe CA: School of American Research 1991; pp. 188-210.

[4] Holston J, Appadurai A. Introduction: Cities and Citizenship. In Holston J, Ed. Cities and Citizenship. Durham NC and London: Duke University Press 1999.

[5] Sandercock L. Cosmopolis II: Mongrel Cities of the $21^{\text {st }}$ Century, London; New York, Continuum 2003.

[6] Fincher R, Jacobs JM. Cities of Difference, New York and London: the Guilford Press 1998.

[7] Sandercock, L. Towards Cosmopolis: Planning for Multicultural Cities, Chichester: John Wiley \& Sons 1998.

[8] Sandercock L. When Strangers become Neighbors: Managing Cities of Difference. Plan Theory Prac 2000; 1: 13-30.

[9] Amin A. Ethnicity and the multicultural city: living with diversity. Environ Plan A 2002; 34: 959-80.

[10] Wood P, Landry C. The Intercultural City: Planning for Diversity Advantage, London and Sterling VA: Earthscan 2008.

[11] Kesten J, Cochrane A, Mohan G, Neal S. Multiculture and Community in New City Spaces. J Intercult Stud 2011; 32: 133-50.

[12] Mueller T, Smets P. Welcome to the neighborhood: social contacts between Iraqis and natives in Arnhem, The Netherlands. Local Environ 2009; 14: 403-15.

[13] Smets, P. Living apart or together? multiculturalism at a neighborhood level. Commun Develop J 2006, 41: 296-306.

[14] Wise A. Hope and belonging in a multicultural suburb. J Intercult Stud 2005; 26: 171-86.

[15] Wise A, Velayutham S, Eds. Everyday Multiculturalism, Hampshire UK, New York, Palgrave Macmillan 2009. 
[16] Lofland LH. The Public Realm: Exploring the city's quintessential social territory. Walter de Gruyter Inc. New York 1998.

[17] US Census 2010. Retrieved on October 9, 2012. Available from http://2010.census.gov/2010census/

[18] Chan FH. Spaces of Negotiation and Engagement in Multi-ethnic Ethnoscapes: The 'Cambodia Town Neighborhood' in Central Long Beach, California." In Hou, J. Ed. Transcultural Cities: Border-Crossing and Placemaking. New York: Routledge 2013.

[19] Cantle T. Community Cohesion: a new framework for race and diversity, Hampshire UK, New York: Palgrave Macmillan 2005.

[20] Kristeva J. Strangers to Ourselves, New York: Columbia University Press 1991.

[21] Maslow AH. Toward a Psychology of Being. $2^{\text {nd }}$ Ed. New York: Van Nostrand Reinhold Company Inc. 1968.

[22] Yuval-Davis N. Belonging and the politics of belonging. Patterns of Prejudice 2006; 40(3):197-214.
[23] Savage M, Bagnall G, Longhurst B. Globalization \& Belonging. London: Sage Publications 2005.

[24] Duyvendak JW. The Politics of Home: belonging and Nostalgia in Western Europe and the United States. New York: Palgrave Macmillan 2011

[25] Devadson R. Cosmopolitanism, Geographical Imaginaries and belonging in North London. Urban Stud 2010; 47: 2945-63.

[26] Fenster T. The right to the gendered city: different formations of belonging in everyday life. J Gender Stud 2005; 14: 217-31.

[27] Barth F. Ed. Ethnic Groups and Boundaries: The social organization of culture difference, Long Grove IL: Waveland Press, Inc. 1969.

[28] Gupta A, Ferguson J, Eds. Anthropological Locations: Boundaries and Grounds of a Field Science, Berkeley and Los Angeles CA, London: University of California Press 1997.

[29] Amin A. The good city. Urban Stud 2006; 43: 1009-23.

Received: April 21, 2012

(C) Felicity Hwee-Hwa Chan; Licensee Bentham Open.

This is an open access article licensed under the terms of the Creative Commons Attribution Non-Commercial License (http://creativecommons.org/licenses/by$\mathrm{nc} / 3.0 /$ ) which permits unrestricted, non-commercial use, distribution and reproduction in any medium, provided the work is properly cited. 